\title{
Communication Practices and Antibiotic Use for Acute Respiratory Tract Infections in Children
}

\author{
Rita Mangione-Smith, $M D, M P H^{1,2}$ \\ Cbuan Zhou, $\mathrm{PbD}^{1,2}$ \\ Jeffrey $D$. Robinson, $P b D^{3}$ \\ James A. Taylor, $M D^{1}$ \\ Marc N. Elliott, $P b D^{4}$ \\ Jobn Heritage, $\mathrm{PbD}^{5}$ \\ 'Department of Pediatrics, University of \\ Washington, Seattle, Washington \\ ${ }^{2}$ Seattle Children's Research Institute, \\ Seattle, Washington \\ ${ }^{3}$ Department of Communication, Portland \\ State University, Portland, Oregon \\ ${ }^{4}$ RAND Corporation, Santa Monica, \\ California \\ ${ }^{5}$ Department of Sociology, University \\ of California, Los Angeles, Los Angeles, \\ California
}

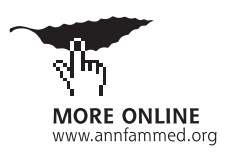

Conflicts of interest: authors report none.

\section{CORRESPONDING AUTHOR}

Rita Mangione-Smith, MD, MPH

University of Washington

Seattle Children's Research Institute

Center for Child Health, Behavior, and

Development

2001 Eighth Avenue, Suite 400

Seattle, WA 98121

Rita.Mangione-Smith@seattlechildrens.org

\begin{abstract}
PURPOSE This study examined relationships between provider communication practices, antibiotic prescribing, and parent care ratings during pediatric visits for acute respiratory tract infection (ARTI).
\end{abstract}

METHODS A cross-sectional study was conducted of 1,285 pediatric visits motivated by ARTI symptoms. Children were seen by 1 of 28 pediatric providers representing 10 practices in Seattle, Washington, between December 2007 and April 2009. Providers completed post-visit surveys reporting on children's presenting symptoms, physical examination findings, assigned diagnoses, and treatments prescribed. Parents completed post-visit surveys reporting on provider communication practices and care ratings for the visit. Multivariate analyses identified key predictors of prescribing antibiotics for ARTI and of parent visit ratings.

RESULTS Suggesting actions parents could take to reduce their child's symptoms (providing positive treatment recommendations) was associated with decreased risk of antibiotic prescribing whether done alone or in combination with negative treatment recommendations (ruling out the need for antibiotics) [adjusted risk ratio (aRR) $0.48 ; 95 \% \mathrm{Cl}, 0.24-0.95$; and aRR 0.15; 95\% Cl, 0.06-0.40, respectively]. Parents receiving combined positive and negative treatment recommendations were more likely to give the highest possible visit rating (aRR 1.16; 95\% Cl, 1.01-1.34).

CONCLUSION Combined use of positive and negative treatment recommendations may reduce the risk of antibiotic prescribing for children with viral ARTIs and at the same time improve visit ratings. With the growing threat of antibiotic resistance at the community and individual level, these communication techniques may assist frontline providers in helping to address this pervasive public health problem.

Ann Fam Med 2015;13:221-227. doi: 10.1370/afm.1785

\section{INTRODUCTION}

A ntibiotic prescribing for childhood acute respiratory tract infections (ARTIs), including acute otitis media, pharyngitis, sinusitis, bronchitis, and upper respiratory infection, is common in the United States. ${ }^{1-3}$ In the outpatient setting, more than $50 \%$ of children diagnosed with ARTIs receive antibiotic prescriptions. ${ }^{1,3}$ Considering that the estimated US prevalence of pediatric bacterial ARTIs is $27 \%,{ }^{3}$ this represents substantial antibiotic overuse nationwide. Unwarranted use of antibiotics is associated with increased resistance among bacteria that commonly cause ARTIs, posing risks to both individuals and communities. ${ }^{4-7}$

Provider-parent communication during visits for viral ARTIs often drives unwarranted antibiotic prescribing. ${ }^{8,9}$ During such visits, providers use 2 main communication formats when recommending treatment:

- Positive treatment recommendations-explanations of what parents can do to help their child's symptoms (for instance, "You can give her a teaspoonful of honey just before bedtime until the cough clears up.")

- Negative treatment recommendations-explanations of the inappropriateness of antibiotics for their child's infection (for instance, "What we have here is just a virus, so antibiotics won't help." $)^{10}$ 
A recent qualitative study of parents attending ARTI visits revealed that they expect advice on symptomatic treatment and feel frustrated by recommendations that no treatment is needed. ${ }^{11}$ In consonance with these qualitative findings, we previously reported that using negative treatment recommendations significantly increases the likelihood that parents will question non-antibiotic treatment plans. ${ }^{8}$ We also found that giving parents a contingency plan (that is, a follow-up plan that includes the possibility of future antibiotic treatment if the child does not improve) is associated with increased visit satisfaction. ${ }^{12}$

During viral ARTI visits, parent questioning of the treatment plan is often interpreted by providers as indicating an expectation for antibiotics. ${ }^{8,9}$ Perceived expectations of antibiotics often change provider decision making into provider-parent negotiation and increase the odds of unwarranted antibiotic prescribing. ${ }^{9,13}$ Thus, for viral ARTI visits, delivering positive treatment recommendations and contingency plans may increase parent acceptance of non-antibiotic treatment plans, decrease unwarranted antibiotic prescribing, and enhance visit satisfaction.

The main objective of this study was to examine whether use of positive and/or negative treatment recommendations and contingency plans is associated with antibiotic prescribing rates for viral ARTIs and parent care ratings for these visits.

\section{METHODS}

We approached 61 eligible pediatric providers from 13 Puget Sound Pediatric Research Network practices in the Seattle, Washington, area over a 4-month period regarding study participation. Twenty-eight providers from 10 practices agreed to participate (46\%) and a subsample of 10 providers each agreed to have 10 study visits videotaped.

\section{Visit Data}

Data were collected from parents of children aged 6 months to 10 years who were seen by participating providers for a chief complaint of ARTI symptoms including cough, nasal congestion, sore throat, ear pain, and ear tugging. Providers supplied data on these visits as well. Data were collected between December 1, 2007, and April 30, 2009, on up to 60 eligible visits to each participating provider. Parents of potentially eligible children were approached before their visit; only those who could read English or Spanish were enrolled. Parents of children who had received antibiotics within the previous 2 weeks or who had already participated were ineligible. Parents and providers gave written informed consent to participate. All study procedures were reviewed and approved by the Seattle Children's Research Institute Institutional Review Board.

\section{Measures}

\section{Parent Post-Visit Survey}

Participating parents completed a post-visit survey immediately after their child's visit with the provider. Using this self-administered survey in English or Spanish, we collected information on family demographics, including parent age, sex, race, ethnicity, education level, household income; child health status, age, and sex; whether the provider spoke the parent's preferred language ${ }_{i}$ how parents rated the care provided $_{i}$ and parent responses to the Provider Communication Behavior Inventory (PCBI).

Provider Communication Behavior Inventory (PCBI). For the PCBI, after their child's visit, parents indicated dichotomously whether the provider used positive treatment recommendations, used negative treatment recommendations, and offered parents a contingency plan.

To test the validity of the PCBI, we videotaped 10 encounters for each of 10 participating providers during the study period. Videotapes were coded using a previously developed interaction analysis coding scheme. ${ }^{8}$ We compared the coded encounters with parent reports of provider communication behaviors on the PCBI. To assess level of agreement, we determined the sensitivity and specificity of parent PCBI reports for correctly identifying when the 3 communication behaviors of interest occurred, treating videotape codes as the gold standard.

\section{Parent Care Ratings}

We assessed parent care ratings using the 10 -point Consumer Assessments of Healthcare Providers and Systems (CAHPS) global rating of care measure: "Using any number from 0 to 10 where 0 is the worst possible care and 10 is the best possible care, what number would you give the care you got from your child's doctor at this visit?"14

\section{Provider Post-Visit Checklist}

Immediately after each study visit, providers completed a post-visit checklist (Supplemental Appendix 1, http:// www.annfammed.org/content/13/3/221/suppl/DC1). On the checklist, the providers indicated the child's presenting symptoms, their physical examination findings, their assigned diagnosis, and their treatment choices. In a prior study using the same provider post-visit checklist ${ }_{1}^{15}$ we found $>90 \%$ agreement between the checklist and medical record documentation for both diagnosis assigned and medications recommended or prescribed. 


\section{Constructing Variables}

The primary visit outcomes of interest were antibiotic prescribing rates for viral ARTIs and parent care ratings for these visits. The primary predictors, based on parent $\mathrm{PCBI}$ responses, were provider use of positive treatment recommendations, negative treatment recommendations, and contingency plans.

\section{Diagnoses}

Bacterial diagnoses on the provider post-visit checklist included acute otitis media, otitis externa, bacterial pneumonia, mycoplasma, streptococcal pharyngitis, and sinusitis. Viral diagnoses included bronchitis, bronchiolitis, croup, otitis media with effusion, viral pharyngitis, viral pneumonia, stomatitis, and viral upper respiratory infection. All cases of bronchitis were considered viral illnesses based on expert consensus that bronchitis is rarely bacterial in children. ${ }^{16}$

\section{Antibiotic Prescribing}

A child was coded as receiving antibiotics if the provider checked "antibiotic" or "antibiotic prescription provided, but parent told not to fill before further contact" (indicating a 'safety-net' or 'delayed' antibiotic prescription) on the post-visit checklist. While some studies have considered provision of a safety-net prescription an alternative to avoiding unwarranted antibiotic prescribing, we considered this practice an acceptable approach only for acute otitis media. ${ }^{17}$ For children assigned viral diagnoses, safety-net antibiotic prescriptions were considered unwarranted prescribing, since some of these prescriptions would ultimately be filled. ${ }^{18}$

\section{Parent Care Ratings}

To be consistent with prior research on parent and patient experience, ${ }^{19-21}$ we dichotomized parent care ratings into high- and lower-rated visit experience using the "top-box" scoring method. ${ }^{22,23}$ That is, we dichotomized responses in analyses to ratings of $10 \mathrm{vs}$ ratings of $0-9$.

\section{Communication Variables}

A provider was classified as giving a positive treatment recommendation when the parent answered "yes" to the following PCBI item: "Did the doctor tell you things you can do to make your child feel better, for example, home remedies you might try?" Providers were classified as giving a negative treatment recommendation if the parent responded "yes" to the following PCBI item: "Did the doctor tell you antibiotics won't help your child get better?" Providers were scored as having given the parent a contingency plan in any of these 3 cases:
- First, the parent could respond "yes" to the item, "Did the doctor say he or she might give your child antibiotics later if your child doesn't get better in the next couple of days?"

- Second, the parent could respond "yes" to both of the following survey items: "Did the doctor ask you to come back if your child isn't doing better in the next day or 2?" and "Did the doctor say he or she might give your child antibiotics if you need to come back?"

- Finally, the parent could respond "yes" to both of the following items, "Did the doctor ask you to call on the phone if your child isn't doing better in the next day or two?" and "Did the doctor say he or she might call in a prescription for antibiotics to the drug store if you call because your child isn't doing any better?"

\section{Analytic Methods}

For all analyses, visits for viral ARTIs were the units of analysis $(\mathrm{n}=794)$. To account for the correlation among observations due to clustering within providers and practices, we applied generalized estimating equations (GEE) with sandwich estimators for standard errors on coefficient estimates. ${ }^{24}$ In addition, the 2 primary outcomes-antibiotic prescribing and parent ratings for the visit—were binary variables. Therefore, to facilitate interpretation, we conducted relative risk regressions by specifying the Poisson family and log link function in the GEE. To further address the possible over-dispersion or under-dispersion issue that often comes with Poisson variance assumption, we included a time-variant scale parameter in the specification of the variance and allowed it to be estimated from data. ${ }^{25}$

The relative risk regression model was used to examine the relationship between use of the 3 communication practices and antibiotic prescribing for viral ARTIs. This model included a 4-level communication variable to indicate the presence of only a positive treatment recommendation $(1,0)$, the presence of only a negative treatment recommendation $(0,1)$, the presence of both types of treatment recommendations $(1,1)$, and the absence of both types of treatment recommendations $(0,0$; the omitted comparison group in all analyses). The model also included a dichotomous indicator of whether a contingency plan was provided, as well as patient and parent demographics found to be associated with antibiotic prescribing for viral ARTIs in a prior study. ${ }^{26}$

We constructed a second relative risk regression model based on GEE to examine the relationships between use of the 3 communication practices and parent care ratings for their child's visit. We entered the same treatment recommendation and contingency plan variables described for the first model and whether the child was prescribed an antibiotic. For consistency with earlier studies using Consumer Assessment of 
Healthcare Providers and Systems (CAHPS) global rating scores as outcomes, ${ }^{27-30}$ we included the following covariates in the model: child health status, sex, and age, parent sex, age, education level, annual income, race, ethnicity, preferred language, provider sex, and whether the provider spoke the parent's preferred language. All analyses were performed using STATA version 12.1 (StataCorp, LP). ${ }^{31}$

\section{RESULTS}

\section{Sample Characteristics}

During the 16-month data collection period, we recruited 1,284 parents whose children were having visits for ARTI symptoms with participating providers, 90 of whom were not eligible because their children did not receive bacterial or viral ARTI diagnoses based on the provider post-visit checklist. Parents were primarily white, non-Hispanic, and highly educated. The mean age for children was 4.2 years (SD 3.0 years), with the majority having excellent or very good health status (Table 1).

\section{Viral ARTI Visit Characteristics}

During this sample of viral ARTI visits, exclusive use of positive treatment recommendations was more com-

\begin{tabular}{|c|c|}
\hline Characteristics & N (\%) \\
\hline \multicolumn{2}{|l|}{ Parents } \\
\hline Female & $999(84 \%)$ \\
\hline \multicolumn{2}{|l|}{ Race $^{a}$} \\
\hline White only & $936(78 \%)$ \\
\hline Asian only & $174(15 \%)$ \\
\hline Black only & $33(3 \%)$ \\
\hline Other & $45(4 \%)$ \\
\hline Hispanic ethnicity & $85(7 \%)$ \\
\hline Annual household income $>\$ 60 \mathrm{~K}$ & $926(78 \%)$ \\
\hline \multicolumn{2}{|l|}{ Education $^{b}$} \\
\hline$<$ High school & $27(2 \%)$ \\
\hline High school graduate & $68(6 \%)$ \\
\hline$<4$ Years of college & $233(20 \%)$ \\
\hline$>4$ year college degree & $863(72 \%)$ \\
\hline Mean age in years & 37.7; SD 7.0 \\
\hline Primary language spoken at home not English & $134(11 \%)$ \\
\hline \multicolumn{2}{|l|}{ Children } \\
\hline Female & $583(49 \%)$ \\
\hline Health status excellent or very good & $1,014(85 \%)$ \\
\hline Mean age in years & $4.2 ; S D, 3.0$ \\
\hline \multicolumn{2}{|l|}{ SD = standard deviation. } \\
\hline \multicolumn{2}{|c|}{$\begin{array}{l}\text { aRace missing for } 6 \text { participating parents; other race = Native Hawaiian or } \\
\text { Pacific Islander, American Indian, and mixed race. } \\
\text { 'Education missing for } 3 \text { participating parents. }\end{array}$} \\
\hline
\end{tabular}

mon than either exclusive use of negative treatment recommendations or the combination of both types of treatment recommendations (Table 2). Overall, antibiotics were prescribed during $34 \%(409 / 1,194)$ of all ARTI visits (bacterial and viral combined), but only during $5 \%$ of viral ARTI visits (42/794). Parent care ratings during visits for viral ARTIs were high, with approximately two-thirds of them rating their child's visit " 10 " on the CAHPS rating scale (Table 2).

\section{Adjusted Associations Between Communication Practices and Outcomes}

Exclusive use of positive treatment recommendations was associated with a $52 \%$ reduction in the risk of antibiotic prescribing for viral ARTIs [adjusted risk ratio $(\mathrm{aRR})=0.48 ; 95 \% \mathrm{CI}, 0.24-0.95 ; P=.04$; Table $3]_{i}$ while using a combination of positive and negative treatment recommendations was associated with an $85 \%$ reduction in the risk of prescribing $(\mathrm{aRR}=0.15$; $95 \% \mathrm{CI}, 0.06-0.40 ; P<.001$; Table 3$)$. Exclusive use of negative treatment recommendations and provision of contingency plans were not associated with antibiotic prescribing rates for viral ARTIs.

Combined use of positive and negative treatment recommendations was associated with a $16 \%$ greater probability of parents giving their child's visit the highest possible rating (10 vs $0-9 ; \mathrm{aRR}=1.16 ; 95 \% \mathrm{CI}$, 1.01-1.34; $P=.04$; Table 4). Exclusive use of positive or negative treatment recommendations and use of contingency plans were not associated with parent visit ratings. Receiving an antibiotic prescription was also not associated with visit ratings (Table 4).

\section{PCBI Validity}

Comparing parent reports of the 3 communication practices to coded videotapes of visits revealed that parents had $87 \%$ sensitivity and $79 \%$ specificity for correctly reporting when positive treatment recommendations

Table 2. Viral Acute Respiratory Infection Visit Characteristics $(\mathrm{N}=794)$

\begin{tabular}{lc}
\hline Visit Characteristics & N (\%) \\
\hline Communication practices & \\
Only positive treatment recommendations provided & $383(48 \%)$ \\
Only negative treatment recommendations provided & $44(6 \%)$ \\
Both positive and negative treatment recommenda- & $255(32 \%)$ \\
$\quad$ tions provided & $182(23 \%)$ \\
$\begin{array}{l}\text { Contingency plan provided } \\
\text { Antibiotics prescribed }\end{array}$ & $42(5 \%)$ \\
Parent-rated care 10 on 0-10 rating scale & $526(66 \%)$ \\
\hline $\begin{array}{l}\text { Note: Viral diagnoses on the provider post-visit checklist included bronchitis, } \\
\text { bronchiolitis, croup, otitis media with effusion, viral pharyngitis, viral pneumo- } \\
\text { nia, stomatitis, and viral upper respiratory infection. }\end{array}$ \\
\hline
\end{tabular}




\begin{tabular}{|c|c|c|c|}
\hline Predictor Variable & $\begin{array}{l}\text { Adjusted } \\
\text { Risk Ratio }^{a}\end{array}$ & $95 \% \mathrm{Cl}$ & $P$ Value \\
\hline \multicolumn{4}{|l|}{ Communication practices } \\
\hline $\begin{array}{l}\text { Only positive treatment recommenda- } \\
\text { tions provided }\end{array}$ & 0.48 & $0.24-0.95$ & .04 \\
\hline $\begin{array}{l}\text { Only negative treatment recommenda- } \\
\text { tions provided }\end{array}$ & 0.18 & $.02-1.43$ & .11 \\
\hline $\begin{array}{l}\text { Both positive and negative treatment } \\
\text { recommendations provided provided }\end{array}$ & 0.15 & $0.06-0.40$ & $<.001$ \\
\hline Contingency plan provided & 1.66 & $0.65-4.23$ & .29 \\
\hline \multicolumn{4}{|c|}{$\begin{array}{l}\text { aAdjusted for provider sex, parent sex, age, race, ethnicity, education level, annual income, lan- } \\
\text { guage spoken at home, child sex, age, and health status. } \\
\text { 'OOmitted comparison group = no treatment recommendation provided. }\end{array}$} \\
\hline
\end{tabular}

\section{Table 4. Adjusted Associations Between Communication Practices During Encounters for Viral Acute Respiratory Infections and Parent Visit Ratings (10 vs $0-9$ )}

\begin{tabular}{|c|c|c|c|}
\hline Predictor Variable & $\begin{array}{l}\text { Adjusted } \\
\text { Risk Ratio }\end{array}$ & $95 \% \mathrm{Cl}$ & $P$ Value \\
\hline \multicolumn{4}{|l|}{ Communication practices } \\
\hline $\begin{array}{l}\text { Only positive treatment recommenda- } \\
\text { tions provided }\end{array}$ & 1.12 & $0.95-1.31$ & .18 \\
\hline $\begin{array}{l}\text { Only negative treatment recommenda- } \\
\text { tions provided }\end{array}$ & 0.99 & $0.71-1.38$ & .94 \\
\hline $\begin{array}{l}\text { Both positive and negative treatment } \\
\text { recommendations provided }{ }^{b}\end{array}$ & 1.16 & $1.01-1.34$ & .04 \\
\hline Contingency plan provided & 0.99 & $0.87-1.14$ & .92 \\
\hline Antibiotic prescribed & 1.13 & $0.95-1.34$ & .16 \\
\hline \multicolumn{4}{|c|}{$\begin{array}{l}\text { aAdjusted risk ratio adjusted for provider sex, whether provider spoke patient's preferred language, } \\
\text { parent sex, age, race, ethnicity, education level, annual income, language spoken at home, child } \\
\text { sex, age, health status. } \\
\text { bOmitted comparison group = no treatment recommendation provided. }\end{array}$} \\
\hline
\end{tabular}

a relationship with decreased antibiotic prescribing; this would likely be at the expense of worse parent care ratings, however. ${ }^{8,11}$ Treatment recommendations using a combination of positive and negative formats, while still relatively infrequent (Table 2), were associated with substantially decreased risk of antibiotic prescribing for viral ARTIs and with high parent visit ratings. To a lesser degree, we also found that exclusive use of positive treatment recommendations was associated with decreased risk of antibiotic prescribing for viral ARTIs, but when used in isolation had no association with parent visit ratings.

Based on the frequency of their respective use, it appears that pediatric providers in this study were more comfortable with making positive treatment recommendations than negative ones. This may be explained by their having been questioned by parents after providing negative treatment recommendations in past visits. ${ }^{8,10}$ Prior qualitative work indicates that providing a negative treatment recommendation after a positive one, rather than in isolation or before a positive recommendation, appeared to have the highest likelihood of attaining parent acceptance of non-antibiotic treatment plans. ${ }^{10}$ The current study lends support to these qualitative findings in that using a combination of positive and negative treatment recommendations was

occurred. Parent sensitivity for accurately reporting on negative treatment recommendations was only $60 \%$; however, specificity was $81 \%$ and overall correct classification occurred in $80 \%$ of cases. Parents had a sensitivity of $100 \%$ and a specificity of $85 \%$ for correctly reporting on the occurrence of contingency plans.

\section{DISCUSSION}

With this study, we have identified key communication practices associated with decreased antibiotic prescribing for viral ARTIs. Given the previously established associations between using negative treatment recommendations, parent questioning of the treatment plan, ${ }^{8}$ and parent-reported frustration with such encounters, ${ }_{1}^{11}$ it is not surprising that exclusive use of negative recommendations during treatment discussions was rare (Table 2). Had this communication practice been used in isolation more frequently, we might have observed associated with an $85 \%$ decrease in risk of antibiotic prescribing during visits for viral ARTIs and significantly increased visit ratings. It is possible that parents see suggestions for symptomatic treatment (positive treatment recommendations) as similar to being given a prescription and thus do not feel they have left emptyhanded as they might when only receiving a negative treatment recommendation. However, because we were unable to assess the order in which positive and negative treatment recommendations occurred, the importance of such sequencing is not yet clear.

Given the exceptionally low rate of antibiotic overuse in the current study (only 5\% of patients with viral diagnoses were prescribed antibiotics) some patients with viral infections may have been assigned bacterial diagnoses in order to justify the decision to prescribe. ${ }^{3,32}$ On the other hand, bacterial diagnoses were given in only $34 \%$ of study visits $(400 / 1,194)$, which is relatively close to the $27 \%$ bacterial prevalence rate 
expected for pediatric ARTIs and substantially below the $49 \%$ national rate of assigning bacterial diagnoses in pediatric ARTI visits. ${ }^{3}$ While the Hawthorne effect may explain some of the presumed overdiagnosis of bacterial illness, ${ }_{1}^{15}$ we hypothesize 2 additional reasons this might have occurred: diagnostic uncertainty and perceived parental pressure to prescribe antibiotics. In cases where the provider is faced with diagnostic uncertainty, use of a contingency plan may allow for the child's illness to evolve and be more clearly classified as viral or bacterial over the ensuing 2 to 3 days. In cases where the provider perceives parental expectations for antibiotics, use of a combination of negative and positive treatment recommendations may allow the provider to gain acceptance from the parent for a nonantibiotic treatment plan.

One study has shown the use of contingency plans to be associated with increased visit satisfaction while simultaneously avoiding antibiotic prescribing for viral illness. ${ }^{12}$ We did not find this to be the case in the current study. One key difference in research design, however, is that the earlier study took parent pre-visit expectations for antibiotics into account. ${ }^{12}$ In that study, receiving a contingency plan was only predictive of higher satisfaction among parents who had a previsit expectation for antibiotics. We did not assess parent pre-visit expectations for antibiotics, thus our study sample likely included both parents who did and those who did not expect to receive antibiotics, decreasing the likelihood of finding a relationship between receiving a contingency plan and care ratings. The current study was also conducted in a different geographic location with a different population of providers and parents; higher and less variable care ratings also limited power to detect differences in this outcome.

The PCBI appears to have good sensitivity and reasonable specificity for determining when positive treatment recommendations and contingency plans occur, but it performs less well in identifying visits where negative treatment recommendations occur. We know from prior work with videotaped encounters that negative treatment recommendations are far less common than positive ones ${ }_{1}^{8}$ so this may make them harder for parents to recall, especially if they occur in combination with a positive recommendation. For both positive treatment recommendations and contingency plans, specificity was lower than sensitivity, with parents tending to report these communication practices as having occurred when they were not observed on videotape. However, prior research related to positive treatment recommendations and parent visit satisfaction suggests that parent perceptions of communication may be more important than actual observed communication practices in terms of predicting positive reports of visit experience. ${ }^{33}$
This study has several limitations. First, the participating providers were from 1 geographic location and were relatively homogeneous in terms of their low prescribing rates for viral ARTIs (5\% among study providers compared to $32 \%$ nationally). ${ }^{3}$ Second, the parent population included primarily non-Hispanic whites with high social and economic status, limiting generalizability. Third, we were unable to objectively verify viral and bacterial diagnoses, which may have led to underestimation of antibiotic prescribing for viral illness. Fourth, due to the observational nature of the study, we have not established a causal link between use of these communication practices and final antibiotic prescribing decisions or care ratings. Fifth, this study was conducted between 2007 and 2009, and prescribing patterns for pediatric ARTI may have changed since then. However, antibiotic prescribing trends over the decade spanning 2001 to 2010 would suggest that this is unlikely. ${ }^{3}$

\section{Conclusions}

Despite these limitations, this study confirms the importance of how treatment recommendations are delivered during visits for viral ARTIs in terms of avoiding unwarranted antibiotic prescribing. It should inform the development of communication-based interventions focused on reducing antibiotic prescribing for viral ARTIs while maintaining positive care experiences for parents.

To read or post commentaries in response to this article, see it online at http://www.annfammed.org/content/13/3/221.

Submitted November 26, 2014; submitted, revised, February 21, 2015; accepted March 4, 2015.

Key words: physician-patient communications; acute respiratory tract infections; antibiotic prescribing; patient satisfaction; visit ratings

Funding support: This study was supported by a grant from the Eunice Kennedy Shriver National Institute of Child Health and Human Development, Grant \# 1R21HD056361-01. The funder had no involvement in the study design, in the collection, analysis, and interpretation of the data; in the writing of the report; or in the decision to submit the article for publication.

Acknowledgements: We would also like to acknowledge the time and effort contributed by the participating providers from the Puget Sound Pediatric Research Network.

Supplementary materials: Available at http://www.AnnFamMed. org/content/13/3/221/suppl/DC1/

\section{References}

1. Grijalva CG, Nuorti JP, Griffin MR. Antibiotic prescription rates for acute respiratory tract infections in US ambulatory settings. JAMA. 2009;302(7):758-766.

2. Hersh AL, Shapiro DJ, Pavia AT, Shah SS. Antibiotic prescribing in ambulatory pediatrics in the United States. Pediatrics. 2011;128(6): 1053-1061. 
3. Kronman MP, Zhou C, Mangione-Smith R. Bacterial prevalence and antimicrobial prescribing trends for acute respiratory tract infections. Pediatrics. 2014;134(4):e956-e965. 10.1542/peds.2014-0605.

4. Pihlajamäki M, Kotilainen $P$, Kaurila T, Klaukka T, Palva E, Huovinen P; Finnish Study Group for Antimicrobial Resistance (FiRe-Network). Macrolide-resistant Streptococcus pneumoniae and use of antimicrobial agents. Clin Infect Dis. 2001;33(4):483-488.

5. Chung A, Perera R, Brueggemann AB, et al. Effect of antibiotic prescribing on antibiotic resistance in individual children in primary care: prospective cohort study. BMJ. 2007;335(7617):429.

6. Goossens H, Ferech M, Vander Stichele R, Elseviers M; ESAC Project Group. Outpatient antibiotic use in Europe and association with resistance: a cross-national database study. Lancet. 2005;365(9459): 579-587.

7. Costelloe C, Metcalfe C, Lovering A, Mant D, Hay AD. Effect of antibiotic prescribing in primary care on antimicrobial resistance in individual patients: systematic review and meta-analysis. BMJ. 2010;340:c2096.

8. Mangione-Smith R, Elliott MN, Stivers T, McDonald LL, Heritage J. Ruling out the need for antibiotics: are we sending the right message? Arch Pediatr Adolesc Med. 2006;160(9):945-952.

9. Cabral C, Horwood J, Hay AD, Lucas PJ. How communication affects prescription decisions in consultations for acute illness in children: a systematic review and meta-ethnography. BMC Fam Pract. 2014;15:63.

10. Stivers T. Non-antibiotic treatment recommendations: delivery formats and implications for parent resistance. Soc Sci Med. 2005;60(5): 949-964.

11. Cabral C, Ingram J, Hay AD, Horwood J; TARGET team. "They just say everything's a virus"-parent's judgment of the credibility of clinician communication in primary care consultations for respiratory tract infections in children: a qualitative study. Patient Educ Couns. 2014;95(2):248-253.

12. Mangione-Smith R, McGlynn EA, Elliott MN, McDonald L, Franz CE, Kravitz RL. Parent expectations for antibiotics, physicianparent communication, and satisfaction. Arch Pediatr Adolesc Med. 2001;155(7):800-806.

13. Mangione-Smith R, McGlynn EA, Elliott MN, Krogstad P, Brook RH. The relationship between perceived parental expectations and pediatrician antimicrobial prescribing behavior. Pediatrics. 1999;103(4 Pt 1): 711-718.

14. CAHPS 2.0 Questionnaires. 2007; https://cahps.ahrq.gov/about.htm. Accessed Jun 5, 2013.

15. Mangione-Smith R, Elliott MN, McDonald L, McGlynn EA. An observational study of antibiotic prescribing behavior and the Hawthorne effect. Health Serv Res. 2002;37(6):1603-1623.

16. O'Brien KL, Dowell SF, Schwartz B, Marcy M, Phillips WR, Gerber MA. Cough illness/bronchitis - principles of judicious use of antimicrobial agents. Pediatrics. 1998;101(Suppl 1):S178-S180.

17. Lieberthal AS, Carroll AE, Chonmaitree T, et al. The diagnosis and management of acute otitis media. Pediatrics. 2013;131(3):e964e999. Erratum in Pediatrics. 2014;133(2):346. Dosage error in article text.
18. Siegel RM, Kiely M, Bien JP, et al. Treatment of otitis media with observation and a safety-net antibiotic prescription. Pediatrics. 2003;112(3 Pt 1):527-531.

19. Rubin HR, Gandek B, Rogers WH, Kosinski M, McHorney CA, Ware JE Jr. Patients' ratings of outpatient visits in different practice settings. Results from the Medical Outcomes Study. JAMA. 1993:270(7):835-840.

20. Wissow LS, Roter D, Bauman LJ, et al. Patient-provider communication during the emergency department care of children with asthma. The National Cooperative Inner-City Asthma Study, National Institute of Allergy and Infectious Diseases, NIH, Bethesda, MD. Med Care. 1998;36(10):1439-1450.

21. Bean-Mayberry BA, Chang CC, McNeil MA, Whittle J, Hayes PM, Scholle SH. Patient satisfaction in women's clinics versus traditional primary care clinics in the Veterans Administration. J Gen Intern Med. 2003;18(3):175-181.

22. Elliott MN, Zaslavsky AM, Goldstein E, et al. Effects of survey mode, patient mix, and nonresponse on CAHPS hospital survey scores. Health Serv Res. 2009;44(2 Pt 1):501-518.

23. Tom JO, Mangione-Smith R, Solomon C, Grossman DC. Integrated personal health record use: association with parent-reported care experiences. Pediatrics. 2012;130(1):e183-e190.

24. Rogers WH. Regression standards in clustered samples. Vol 3. College Station, TX: STATA Press; 1993.

25. Zou GY, Donner A. Extension of the modified Poisson regression model to prospective studies with correlated binary data. Stat Methods Med Res. 2013;22(6):661-670.

26. Mangione-Smith R, Elliott MN, Stivers T, McDonald L, Heritage J, McGlynn EA. Racial/ethnic variation in parent expectations for antibiotics: implications for public health campaigns. Pediatrics. 2004; 113(5):e385-e394.

27. Wilkins V, Elliott MN, Richardson A, Lozano P, Mangione-Smith R. The association between care experiences and parent ratings of care for different racial, ethnic, and language groups in a Medicaid population. Health Serv Res. 2011;46(3):821-839.

28. Zaslavsky AM, Zaborski L, Cleary PD. Does the effect of respondent characteristics on consumer assessments vary across health plans? Med Care Res Rev. 2000;57(3):379-394.

29. Elliott MN, Swartz R, Adams J, Spritzer KL, Hays RD. Case-mix adjustment of the National CAHPS benchmarking data 1.0: a violation of model assumptions? Health Serv Res. 2001;36(3):555-573.

30. O'Malley AJ, Zaslavsky AM, Elliott MN, Zaborski L, Cleary PD. Case-mix adjustment of the CAHPS Hospital Survey. Health Serv Res. 2005;40(6 Pt 2):2162-2181.

31. STATA Statistical Software Release 12 [computer program]. College Station, TX: StataCorp LP; 2011.

32. Cox ED, Saluja S. Criteria-based diagnosis and antibiotic overuse for upper respiratory infections. Ambul Pediatr. 2008;8(4):250-254.

33. Beckett MK, Elliott MN, Richardson A, Mangione-Smith R. Outpatient satisfaction: the role of nominal versus perceived communication. Health Serv Res. 2009;44(5 Pt 1):1735-1749. 